\title{
Endoscopic full-thickness resection of a non-lifting large laterally spreading flat colonic polyp
}

Resection of a non-lifting large laterally spreading flat colonic polyp can be challenging. A 44-year-old Hispanic woman with a history of hereditary non-polyposis colorectal cancer syndrome (HNPCC) was referred for removal of a laterally spreading polyp.

Colonoscopy showed a 2-cm laterally spreading flat polyp in the proximal transverse colon ( Video 1; $>$ Fig. 1a). Submucosal injection was performed using a solution of saline, methylene blue, and epinephrine $(1: 200000)$ but the polyp could not be lifted despite inject-

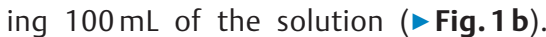
Because of the flat and central non-lifting nature of the polyp, it could not be engaged with available snares. A decision was made to perform an endoscopic fullthickness resection using a band device.

A band mucosectomy kit was used, with a band being placed at the base of the polyp. The resection was performed using a hot snare below the band. After the resection, a full-thickness defect of approximately $2 \mathrm{~cm}$ was seen at the site

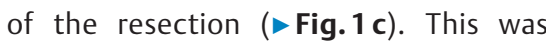
then completely closed using a 14/6 type 't' over-the-scope clip (OTSC) ( $\triangleright$ Fig. 1 d). A computed tomography (CT) scan of the abdomen with oral contrast after the procedure showed free peritoneal air but no leak of the oral contrast at the site of OTSC. The patient reported minimal abdominal discomfort due to the free peritoneal carbon dioxide for a few hours after the procedure, which resolved spontaneously. The patient was kept under observation for 12 hours and discharged on prophylactic antibiotics. Pathology revealed the full-thickness re- section of a tubular adenoma with areas of focal high grade dysplasia and negative margins.

We conclude that full-thickness resection of a large non-lifting laterally spreading polyp can be performed using a band endoscopic mucosal resection technique and an OTSC can be used for successful closure of the full-thickness colonic defect, thereby decreasing the morbidity associated with surgery.

Endoscopy_UCTN_Code_TTT_1AO_2AG

\section{Competing interests}

None

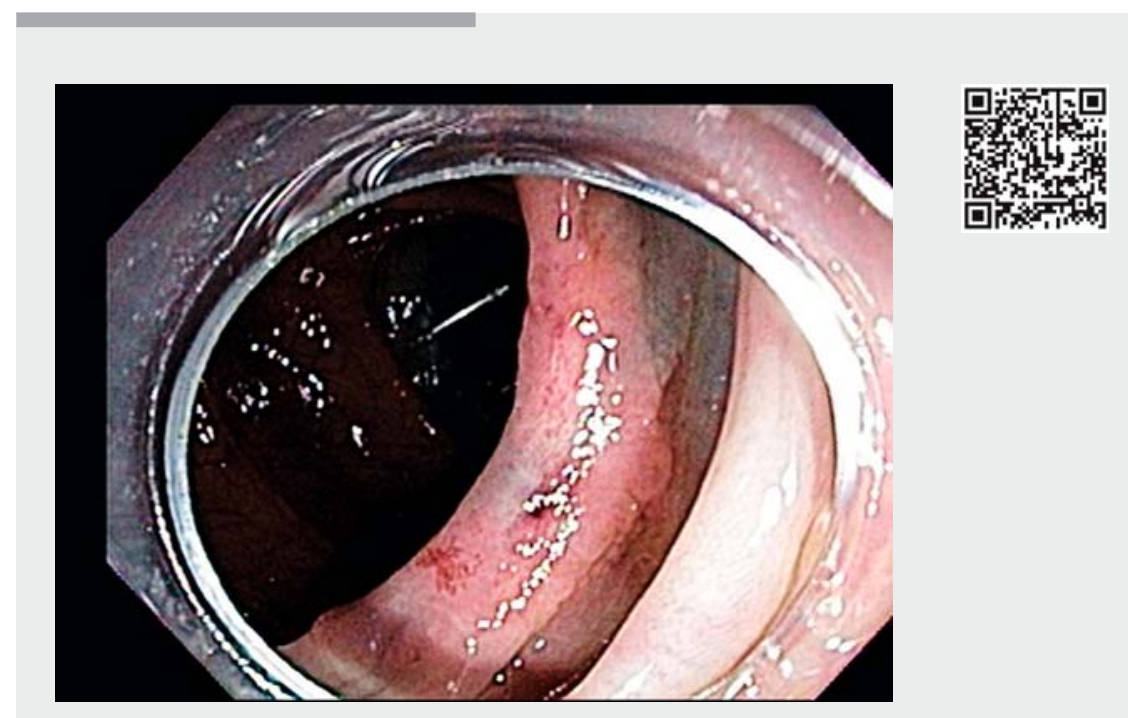

Video 1 Endoscopic full-thickness resection of a non-lifting large laterally spreading flat colonic polyp, with subsequent computed tomography scan and histology images. 

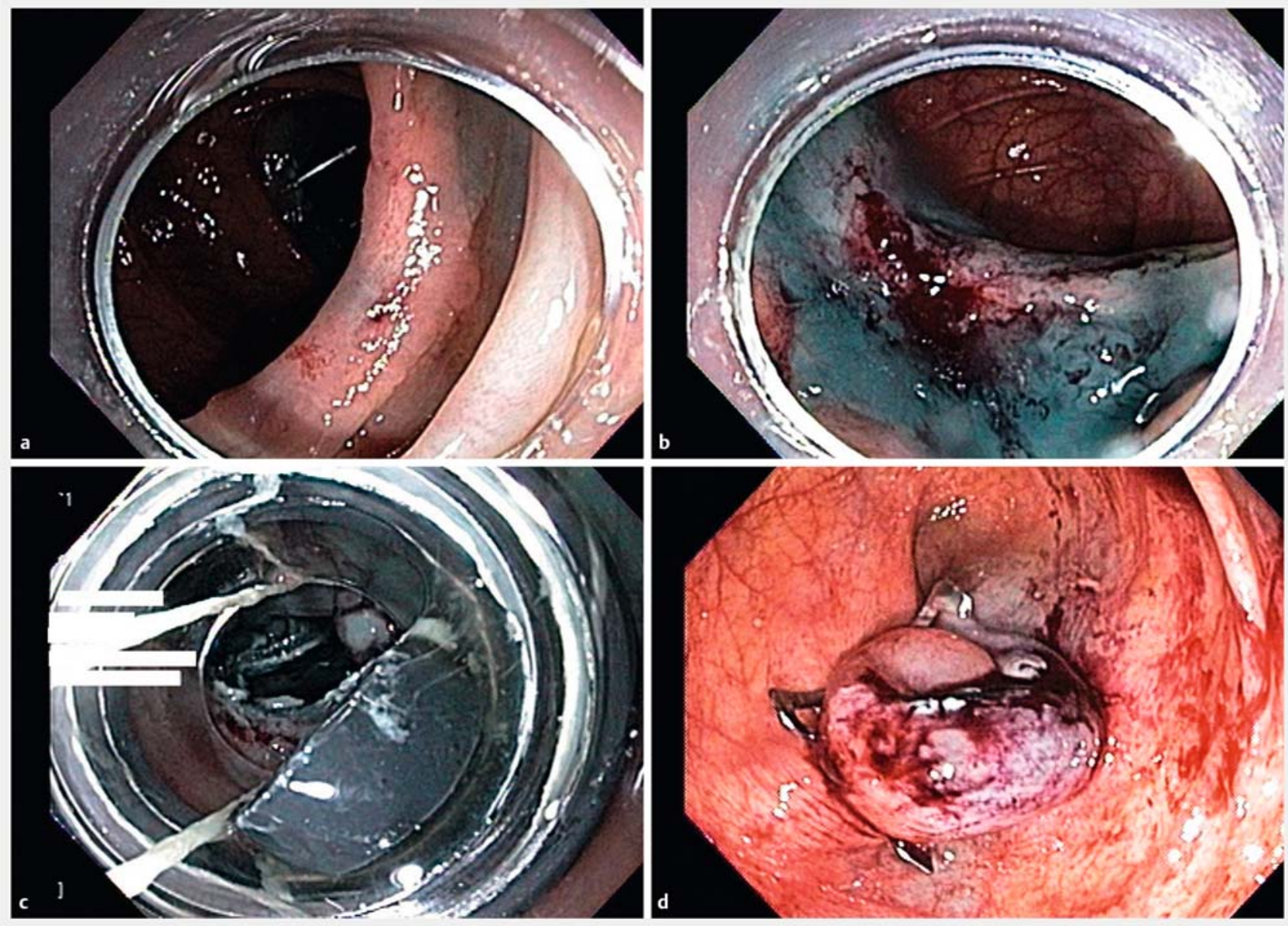

Fig. 1 Endoscopic images showing: a a large laterally spreading flat colonic polyp; b non-lifting of the polyp after submucosal injection; $\mathbf{c}$ the full-thickness mucosal defect at the polyp resection site; $\mathbf{d}$ complete closure of the mucosal defect using an over-the-scope clip.

Corresponding author

\section{Shashideep Singhal, MD}

6431 Fannin street, MSB 4.232 Houston, TX 77030, USA

Fax: +1-713-500-6699

sdsinghal@gmail.com
Bibliography

DOI https://doi.org/10.1055/s-0043-109553

Endoscopy 2017; 49: E171-E172

(c) Georg Thieme Verlag KG

Stuttgart · New York

ISSN 0013-726X

ENDOSCOPY E-VIDEOS
https://eref.thieme.de/e-videos

endoscopy. All papers include a high quality video and all contributions are freely accessible online.

This section has its own submission website at

https://mc.manuscriptcentral.com/e-videos 